\title{
PERANAN PELATIHAN DALAM UPAYA PENINGKATAN PRODUKTIVITAS KERJA KARYAWAN DI LINGKUNGAN DEPARTEMEN PEKERJAAN UMUM
}

\section{Saridawati}

Universitas Bina Sarana Informatika

Email : sarida_wati@yahoo.co.id

\section{Abstract}

Human resources is one of the most important in an organization or management. For that reason, Human Resources can utilize the workforce so that organizational is done efficiently as well as the excitement of working. To improve the ability of employees / employees can be done by developing employee skills, in this case is education and training. Education and training in the education and training center of Department of Public Works employees is to realize a capable workforce for existing trainings in the education and training center of Department of Public Works employees must be planned, implemented and directed so ensure the existence of education and training activities that are aligned with needs Department of Public Work is support fully the achievement of the objectives of the Department of Public Works.

Keywords: Training and Productivity of work.

\begin{abstract}
Abstrak
Sumber daya manusia merupakan salah satu sumber daya manusia yang sangat penting dalam suatu organisasi atau manajemen. Untuk itu Sumber Daya Manusia dapat memanfaatkan tenaga kerja sehingga tujuan organisasi dilaksanakan secara berdayaguna sekaligus adanya kegairahan bekerja. Untuk meningkatkan kemampuan pegawai/karyawan dapat dilakukan dengan pengembangan kecakapan pegawai, dalam hal ini pendidikan dan pelatihan. Pendidikan dan pelatihan di Pusdiklat pegawai Departemen Pekerjaan Umum adalah untuk mewujudkan angkatan kerja yang cakap guna pelatihan-pelatihan yang ada di Pusat Pendidikan dan Pelatihan Pegawai Departemen Pekerjaan Umum harus direncakan, dilaksanakan dan diarahkan guna menjamin adannya kegiatan pendidikan dan pelatihan yang selaras dengan kebutuhan Departemen Pekerjaan Umum menunjang sepenuhnya pencapaian tujuan Departemen Pekerjaan Umum.
\end{abstract}

Kata kunci : Pelatihan, Produktivitas kerja

\section{Pendahuluan}

Dalam era pembangunan jangka panjang nasional masalah sumber daya manusia (SDM) merupakan masalah yang sentris dan menjadi tanggung jawab semua lembaga. Karena pada dasarnya sumber daya manusia merupakan modal utama bagi perusahaan dalam membangun persaingan bisnis. Sumber daya manusia merupakan bagian penting 
dalam aktivitas kerja. Karena hal tersebut berhubungan dengan masalah kualitas kerja dan pencapaian kerja (Saridawati, 2018). Masalah SDM tidak bisa hanya dilihat dari segi kuantitas dan kualitas saja, tetapi harus juga dilihat dari segi kemampuan menciptakan sistim kerja yang produktif bagi pembangunan di berbagai bidang. Perencanaan ketenagakerjaan/sumber daya manusia bidang pekerjaan umum untuk menunjang kebutuhan pembangunan nasional di masa mendatang mengorientasikan pada program pelatihan pegawai.

Kebutuhan penyediaan tenaga kerja yang mampu dan trampil dibidang pekerjaan umum semakin meningkat dari tahun ke tahun, sejalan dengan meningkatnya pembangunan sektor-sektor strategis yang membutuhkan pelayanan prasarana dan sarana dasar (PSD). Cakupan beban tugas bidang ke-PU-an semakin bertambah kompleks dan luas, untuk menanganinya dibutuhkan kualifikasi sumber daya manusia sebagai pelaksana, berupa angkatan kerja yang trampil, siap tugas dan mempunyai sikap positif dalam pelaksanaan program pembangunan bidang pekerjaan umum. Tenagatenaga trampil tersebut di dalam pelaksanaan tugas membutuhkan bekal pengetahuan dan ketrampilan yang relevan dengan bidang tugas yang menjadi tanggung jawabnya, serta pembinaan secara berkesinambungan, antara lain melalui.

1. Jalur karier, dengan adanya pekerjaan (tugas/jabatan) yang sesuai dengan kemampuannya, penghargaan yang diberikan sesuai dengan prestasi kerja yang dapat dicapai, dan kemungkinan adanya motifasi pengembangan diri (self development).

2. Jalur pendidikan dan pelatihan sebagai penunjang jalur karier dengan tujuan memberikan bekal pengetahuan dan keterampilan untuk kemudahan dalam pelaksanaan tugas, pembentukan tenaga-tenaga profesional, serta memberikan pengaruh untuk bersikap positif terhadap pelaksanaan program pembangunan.

Pusat pendidikan dan pelatihan (Pusdiklat) pegawai Departemen Pekerjaan Umum mempunyai tugas melaksanakan pendidikan dan pelatihan pegawai dilingkungan Departemen Pekerjaan Umum berdasarkan kebijaksanaan yang ditetapkan oleh Menteri dan Peraturan Perundang-Undangan yang berlaku, dengan sasaran populasi ditujukan untuk memenuhi kemampuan tenaga kerja dibidang yaitu:

1. Kepemimpinan (Managerial Skill)

2. Keahlian Teknis (Technical Skill)

Pada dasarnya berbagai kegiatan atau program pelatihan adalah dalam upaya meningkatkan produktivitas sumber daya manusia yang berkenaan dengan peningkatan pelayanan yang baik pada masyarakat dalam bentuk penyediaan prasarana dan sarana dasar ke-PU-an.

Disamping itu pengaruh dari era globalisasi, dimana Indonesia turut berkelompok atas dasar kepemimpinan ekonomi dalam organisasi AFTA, APEC dan WTO menuntut konsekwensi penguasaan ilmu pengetahuan dan teknologi (IPTEK) guna efisiensi produksi serta penghapusan hambatan perdagangan, untuk dapat berkompetisi dalam kelompok tersebut sudah dirasakan perlu dilaksanakan peningkatan produktivitas sumber daya manusia yang produktif. 
Sebelum dijelaskan mengenai manajemen sumber daya manusia secara mendalam, ada baiknya kita ketahui terlebih dahulu pengertian manajemen secara umum (Terry, 1986) mendefinisikan bahwa "Manajemen adalah merupakan sebuah proses yang khas, yang terdiri dari tindakan-tindakan perencanaan, pengorganisasian, menggerakkan dan pengawasan, yang dilakukan untuk menentukan serta mencapai sasaran-sasaran yang telah ditetapkan memulai pemanfaatan sumber daya manusia serta sumber-sumber lainnya" Dengan perkataan lain terdapat adanya aktivitas-akvitas khusus yang merupakan bagian dari pada suatu proses manajemen. Disamping itu dapat dikatakan bahwa aktivitas-aktivitas tersebut dilakukan untuk mencapai sasaran-sasaran yang ditetapkan sebelumnya dan pelaksanaan berlangsung dengan bantuan manusia dengan sumber-sumber daya lainnya.

Setelah kita mengetahui pengertian Manajemen secara umum, selanjutnya akan dijelaskan mengenai pengertian manajemen sumber daya manusia, istilah manajemen sumber daya manusia memiliki istilah lain yang mempunyai pengertian yang sama, berbagai istilah digunakan untuk pengertian manajemen sumber daya manusia (MSDM), antara lain, Manajemen Sumber Daya Insani, Manajemen Personalia, Manajemen Kepegawaian, Manajemen Perburuhan, Manajemen Tenaga Kerja, Administrasi Personalia (kepegawaian) dan hubungan industrial (Moh Agus Tulus, 1993).

Manajemen Sumber Daya Manusia adalah perencanaan, pengorganisasian, pengarahan dan pengawasan atas pengadaan, pengembangan, pemberian kompensasi, pengintegrasian, pemeliharaan dan pemutusan hubungan kerja dengan maksud untuk membantu mencapai tujuan perusahaan, individu dan masyarakat (Edwin B. Flippo, 1992).

\section{Metode Penelitian}

Objek penelitian adalah tentang kebijakan pendidikan dan latihan dalam rangka upaya meningkatkan produktivitas sumber daya manusia yang diterapkan oleh Pusat Pendidikan dan Pelatihan Pegawai PU. Metode Pengumpulan Data menggunakan dua cara, yaitu : penelitian kepustakaan (Library Research) dan penelitian lapangan (Field Research). Penelitian lapangan adalah suatu metode yang digunakan untuk mengumpulkan data primer yang diperlukan dalam penelitian, melalui wawancara dengan pejabat maupun dengan petugas yang ditunjuk oleh Pusat Pendidikan dan Pelatihan Pegawai PU Jakarta.

Untuk mengukur variabel pelatihan dan variabel produktivitas tenaga kerja digunakan quistioner (angket) yang diberikan kepada 25 orang responden. Indikator yang digunakan untuk produktivitas tenaga kerja adalah ketrampilan kerja dan hasil kerja (Ravianto, 1985). Sedangkan untuk mengetahui derajat hubungan antara pelatihan terhadap produktivitas tenaga kerja digunakan "koefisien korelasi jenjang spearman" dengan rumus :

$\mathrm{r}_{\mathrm{s}}=\frac{1-6 \Sigma \mathrm{di}^{2}}{\mathrm{n}\left(\mathrm{n}^{2}-1\right)}$ 
dimana :

$\mathrm{r}_{\mathrm{s}}=$ koefisien korelasi

$\mathrm{n}$ = banyaknya sampel

di $=$ selisih rangking pasangan sampel .

Untuk mengetahui besarnya pengaruh pelatihan terhadap produktivitas kerja dapat digunakan koefisien determinasi yaitu kuadrat dari koefisien determinasi $\mathrm{x} 100 \%(\mathrm{Cd}=$ $\left.\left(\mathrm{r}_{\mathrm{s}}\right)^{2} \times 100 \%\right)$

\section{Hasil dan Pembahasan}

\section{A. Program Pelatihan Pada Pusat Pendidikan dan Pelatihan Departemen Pekerjaan Umum.}

Tujuan akhir Pendidikan dan Pelatihan adalah untuk mewujudkan angkatan kerja yang cakap guna menunjang sepenuhnya pencapaian tujuan Departemen Pekerjaan Umum agar DIKLAT menjadi produktif dalam menunjang kegiatan Departemen Pekerjaan Umum, maka kegiatan DIKLAT harus direncanakan, dilaksanakan dan diarahkan guna menjamin adanya kegiatan DIKLAT yang selaras dengan kebutuhan Departemen Pekerjaan Umum. Rencana dan program pelaksanaan Pendidikan dan Pelatihan :

1. Jangka Pendek

a. Menyelesaikan program DIKLAT yang telah komitmen dengan pihak luar Departemen Pekerjaan Umum seperti program kerja sama dengan Kabupaten

b. Menyelesaiakan kebutuhan pelatihan struktural penjenjangan (ADUM, SPAMA, SPAMEN, dan SPATI) .

c. Pemanfaatan produk penunjang yang berkaitan dengan pembinaan personil DIKLAT, institusi, pola DIKLAT dan aspek hukum serta manajemen informasi DIKLAT untuk persiapan peningkatan sumber daya manusia bidang pekerjaan umum.

d. Identifikasi penetapan kurikulum standar khusus bidang teknik umum dan tata laksana.

e. Menyelenggarakan pelatihan singkat yang dibutuhkan dibidang Pengairan, Bina Marga, Cipta Karya dan Teknik Umum Tata Laksana.

2. Program Jangka Menengah

a. Melanjutkan prioritas dari kegiatan komitmen dalam pendidikan dan pelatihan.

b. Mengembangkan TMIS (Training Management Information System). Sampai dengan Pendidikan dan Pelatihan Pekerjaan Umum Wilayah

c. Peningkatan staf Pendidikan dan Pelatihan dan widyaiswara dalam rangka pembinaan profesionalisme di bidang Pendidikan dan Pelatihan dalam dan luar negeri.

d. Memanfaatkan hasil DIKLAT untuk penyempurnaan proses DIKLAT. 
3. Program Jangka Panjang

a. Penyeragaman pelatihan untuk tingkat manajer melalui Pendidikan dan Pelatihan struktural.

b. Modul-modul DIKLAT untuk penjenjangan fungsional untuk segala jenis kemampuan dan tingkatan beserta akreditasinya yang telah disesuaikan dengan pola perencanaan tenaga kerja.

c. Pemanfaatan sistem informasi Pendidikan dan Pelatihan dalam menunjang fungsi-fungsi manajemen Pendidikan dan Pelatihan bidang ke-PU-an.

d. Pemanfaatan dan penyempurnaan institusi dan kelembagaan yang terkait dengan proses Pendidikan dan Pelatihan untuk menunjang kelancaran mekanisme dalam penyelenggaraan Pendidikan dan Pelatihan.

\section{B. Pelaksnaaan Pelatihan Pada Pusat Pendidikan dan Pelatihan Departemen Pekerjaan Umum.}

Produk statuta yang menjadi landasan operasional penyelenggaraan pelatihan di Pusat Pendidikan dan Pelatihan Pegawai Departemen Pekerjaan Umum saat ini diatur oleh keputusan Menteri PU No. 211/KPTS/1994 yang telah diadakan peninjauan kembali sesuai dengan perkembangan kebutuhan dan beban kerja PUSDIKLAT yang semakin berkembang.

Tujuan Pendidikan dan Pelatihan berdasarkan Peraturan Pemerintah Republik Indonesia No. 101 tahun 2000 tentang Pendidikan dan Pelatihan jabatan pegawai negeri sipil adalah :

1. Meningkatkan kesetiaan dan ketaatan pegawai kepada Pancasila, UndangUndang Dasar 1945, negara dan Pemerintah Republik Indonesia.

2. Menanamkan persamaan pola pikir yang dinamis dan bernalar agar memiliki wawasan yang konprehensif untuk melaksanakan tugas umum pemerintahan dan pembangunan.

3. Memantapkan semangat pengabdian yang berorientasi pada pelayanan dan pengembangan partisipasi masyarakat.

4. Meningkatkan pengetahuan, keahlian dan atau keterampilan. serta pembentukan sedini mungkin kepribadian pegawai.

Pendidikan dan Pelatihan terdiri dari :

1. Pendidikan dan Pelatihan Prajabatan

2. Pendidikan dan Pelatihan dalam jabatan Pendidikan dan Pelatihan Prajabatan adalah Pendidikan dan Pelatihan yang dipersyaratkan dalam pengangkatan Pegawai. Pendidikan dan Pelatihan dalam Jabatan adalah Pendidikan dan Pelatihan bagi Pegawai Negeri Sipil yang terdiri dari :

- Pendidikan dan Pelatihan struktural

- Pendidikan dan Pelatihan fungsional

- Pendidikan dan Pelatihan teknis.

Pendidikan dan Pelatihan struktural adalah Pendidikan dan Pelatihan yang dipersyaratkan bagi pegawai negeri yang akan diangkat dalam jabatan struktural, Pendidikan dan Pelatihan struktural terdiri dari : 
a. Pendidikan dan Pelatihan staf pimpinan administrasi tingkat pertama yang selanjutnya disebut DIKLAT SPAMA, yaitu DIKLAT yang dlpersyaratkan bagi pegawai yang terpilih dan memiliki kemampuan untuk diangkat dalam jabatan struktural eselon III.

b. Pendidikan dan Pelatihan Staf dan Pimpinan administrasi tingkat menengah yang selanjutnya disebut DIKLAT SPAMEN, yaitu Pendidikan dan Pelatihan yang dipersyaratkan bagi pegawai yang terpilih dan memiliki kemampuan untuk diangkat dalam jabatan struktural eselon II.

c. Pendidikan dan Pelatihan Staf dan Pimpinan Administrasi tingkat tinggi yang selanjutnya disebut DIKLAT SPATI, yaitu Pendidikan dan Pelatihan yang dipersyaratkan bagi pegawai yang telah menduduki jabatan struktural eselon II yang terpilih serta memiliki kemampuan untuk diangkat dalam jabatan struktural eselon I.

Sebelum Pendidikan dan Pelatihan struktural sebagaimana tersebut diatas kepada pegawai negeri diberikan Pendidikan dan Pelatihan administrasi umum (ADUM). Pendidikan dan Pelatihan fungsional adalah Pendidikan dan Pelatihan yang dipersyaratkan bagi pegawai yang akan dan telah menduduki jabatan fungsional.

Pendidikan dan Pelatihan Teknik adalah Pendidikan dan Pelatihan yang diselenggarakan untuk memberikan ketrampilan atau penguasaan pengetahuan dibidang teknis tertentu, sehingga mampu melaksanakan tugas dan tanggung jawab yang diberikan dengan sebaik-baiknya seperti contoh :

- Pelatihan bidang irigasi jenis pelatihannya adalah khusus ekploitasi dan pemeliharaan irigasi, pelatihan teknik perencanaan irigasi, pelatihan teknik pengembangan irigasi idang konstruksi.

- Pelatihan bidang rawa jenis pelatihannya adalah supervisi konstruksi rawa, latihan ekploitasi dan pemeliharaan rawa dan lain-lain.

\section{Evaluasi Hasil Pelatihan pada Pusat Pendidikan dan Pelatihan Departemen Pekerjaan Umum.}

Evaluasi pelatihan adalah suatu kegiatan untuk mengukur kadar keberhasilan suatu pelatihan atau suatu kegiatan untuk menentukan perbedaan antara tujuan yang telah ditetapkan untuk dibandingkan dengan hasil yang dicapai (perbedaan antara rencana dan pelaksanaan). Evaluasi pelatihan memberi umpan balik yang esensial bagi berbagai tingkat manajemen. Tujuan evaluasi adalah untuk meningkatkan efektivitas seluruh proses manajemen pelatihan sampai pada pelaksanaan teknis belajar-mengajar yaitu untuk :

1. Menentukan apakah tujuan-tujuan program pelatihan tercapai.

2. Menunjukkan kelemahan dan kekuatan program.

3. Menentukan apakah program pelatihan sudah memadai, memungkinkan para peserta mengetahui bagaimana mereka memperoleh kemajuan dalam belajar dan juga untuk mengukur kelemahan dan kekuatan mereka sendiri. 
4. Memberikan berbagai informasi yang berguna pada organisasi dan dapat membantu pimpinan dalam menentukan keputusan yang rasional.

5. Merupakan sistem umpan-balik yang terorganisasi dan memungkinkan perencana dan pemuat kebijaksanaan untuk membuat keputusan yang lebih baik lagi.

Sample pelatihan di Direktorat Jenderal Pengairan sebanyak 25 orang peserta, jenis pelatihan tersebut adalah ekploitasi dan pemeliharaan rawa yang terdiri dari kurikulum/materi sebagai berikut :

1. PTEP : Proses perencanaan teknik ekploitasi dan pemeliharaan rawa.

2. PKPR : Pelaksanaan konstruksi pemeliharaan rehabilitasi dan peningkatan.

3. PEP : Proses ekploitasi dan pemeliharaan

4. APP : Aspek produksi dan pendapatan petani

5. PML : Pemanfaatan lahan.

6. Questioner lihat (lampiran)

skala penilaian dengan skala ordinal

1. Kurang

2. Cukup

3. Baik

4. Baik sekali.

Jenis penilaian/evaluasi pelatihan (indikasi yang yang dinilai) :

1. Penilaian keseluruhan pelatihan dan kunjungan lapangan.

2. Penilaian pokok bahasan tertentu.

3. Penilaian instruktur tertentu.

4. Pengelolaan keseluruhan pelatihan.

5. Penilaian pengetahuan peserta (pra test dan post test)

Hasil penilaian :

Dari questioner sampel sebanyak 25 orang terhadap :

- Penilaian keseluruhan pelatihan dan kunjungan lapangan diperoleh nilai ratarata 2,75

- Penilaian pokok bahasan tertentu ................................................ 2,79

- Penilaian instruktur tertentu .............................................................. 2,74

- Penilaian pengelolaan keseluruhan pelatihan ................................... 2,76

- Penilaian pengetahuan peserta (pra test post test) ........................... 2,88

\begin{tabular}{|c|c|c|c|c|c|c|}
\hline & PTEP & PKPR & PEP & APP & PML & Rata-rata \\
\hline $\begin{array}{l}\text { - } \begin{array}{l}\text { Skor total (penambahan } \\
\text { pengetahuan) }\end{array} \\
\text { netal }\end{array}$ & 92 & 95 & 99 & 102 & 97 & 97 \\
\hline $\begin{array}{l}\text { Rata-rata penambahan } \\
\text { pengetahuan/ orang }\end{array}$ & 3.68 & 3.8 & 3.96 & 4.08 & 3.88 & 3.88 \\
\hline $\begin{array}{l}\text { prosentase penambahan } \\
\text { pengetahuan }\end{array}$ & $148 \%$ & $158 \%$ & $155 \%$ & $185 \%$ & $170 \%$ & $163.2 \%$ \\
\hline
\end{tabular}


Dari angka diatas terlihat terdapat kemajuan penambahan pengetahuan rata-rata sebesar 163,2\% atau dengan nilai 97 katagori (baik, baik sekali).

\section{Peroduktivitas Kerja}

Peningaktan produktivitas tidak selalu berarti meningkatkan produksi melalui sumber daya melainkan mengerjakan secara lebih baik dengan apa yang ada. Dalam hubungannya dengan sutnber daya manusia berarti mengerjakan secara lebih baik dengan apa yang ada dan memerlukan adanya peningkatan kemampuan, pengetahuan, sikap dan tingkah laku yang kesemuanya itu diperoleh melalui pelatihan.

Banyak pengertian produktivitas yang terdapat dalam referensi. Untuk menghitung tingkat produktivitas kerja di Departemen Pekerjaan Umum digunakan rumusan sebagai berikut

\section{Tabel 2}

Tingkat Produktivitas di PUSDIKLAT Pegawai Departemen Pekerjaan Umum Target 5 Tahun $(2000 / 2001-2004 / 2005$

\begin{tabular}{ccc}
\hline \multirow{2}{*}{ Tahun } & Realisasi & \multirow{2}{*}{ Tingkat Produktivitas } \\
\cline { 2 - 2 } $2000 / 2001$ & target $\times$ hari kerja $\times$ tng kerja & 0,000000785 \\
\hline & 46.900 & 0,000000775 \\
\hline $2001 / 2002$ & $46.908 \times 334 \times 38.150$ & 0,000000782 \\
\hline $2002 / 2003$ & 47.200 & 0,000000781 \\
\hline $2003 / 2004$ & $47.229 \times 334 \times 38.150$ & 0,000000782 \\
\hline
\end{tabular}

Ket - Realisasi dan target dalam jutaan rupiah.

Tabel 3

Tingkat Produktivitas di Bidang DIKLAT Pengairan (Direktorat Jenderal Pengairan Departemen Pekerjaan Umum) Target 5 Tahun $(2000 / 2001-2004 / 2005)$

\begin{tabular}{|c|c|c|}
\hline \multirow{2}{*}{ Tahun } & Realisasi & \multirow{2}{*}{ Tingkat Produktivitas } \\
\hline & target $\mathrm{x}$ hari kerja $\mathrm{x}$ tng kerja & \\
\hline \multirow{2}{*}{$2000 / 2001$} & 1.700 & \multirow{2}{*}{0,000000382} \\
\hline & $1.800 \quad \mathrm{x} \quad 334 \quad \mathrm{X} \quad 7.407$ & \\
\hline \multirow{2}{*}{$2001 / 2002$} & 2.050 & \multirow{2}{*}{0,000000398} \\
\hline & $2.090 \times 334 \quad x \quad 7.407$ & \\
\hline \multirow{2}{*}{$2002 / 2003$} & 2.184 & \multirow{2}{*}{0,000000402} \\
\hline & $2.195 \times 334 \times 7.407$ & \\
\hline \multirow{2}{*}{$2003 / 2004$} & 2.395 & \multirow{2}{*}{0,000000410} \\
\hline & $2.415 \times 334 \times 7.407$ & \\
\hline \multirow{2}{*}{$2004 / 2005$} & 2.500 & \multirow{2}{*}{0,000000372} \\
\hline & $2.715 \times 334 \times 7.407$ & \\
\hline
\end{tabular}

Sumber data primer yang telah diolah 
Ket : Realisasi dan target dalam jutaan rupiah.

Dari tabel perhitungan diatas yaitu data tentang target dan realisasinya dan dengan memperhatikan sumber daya yang dipakai kemudian dibandingkan, terungkap bahwa produktivitas kerja atas dasar perbandingan realisasi dengan target kali hari kerja kali tenaga kerja dari tahun anggaran 2000/2001 s/d 2004/2005 produktivitasnya sudah positif namun relatif kecil.

\section{E Peranan Pelatihan Dalam Rangka Meningkatkan Produktivitas Kerja.}

Dalam menganalisis peranan pelatihan terhadap peningkatan produktivitas kerja yang dilaksanakan oleh Pusat Pendidikan dan Pelatihan Pegawai Departemen Pekerjaan Umum, penulis menggunakan analisis koefisien korelasi jenjang spearman dengan rumus

$$
\mathrm{r}_{\mathrm{s}}=\frac{1-6 \sum \mathrm{d}_{\mathrm{i}}^{2}}{\mathrm{n}\left(\mathrm{n}^{2-1}\right)}
$$

Dimana : $\mathrm{r}_{\mathrm{s}}=$ koefisien korelasi

$\mathrm{n}=$ banyaknya sampel

$\mathrm{d}_{\mathrm{i}}=$ selisih rangking pasang sampel

Untuk menganalisis peranan pelatihan dengan produktivitas kerja tersebut diperlukan data. Data dibawah ini adalah merupakan hasil penilaian pelatihan dengan produktivitas kerja yang dilakukan. Terhadap peserta pelatihan. "Ekploitasi dan pemeliharaan rawa" pada Direktorat Jenderal Pengairan yang dijadikan sampel. Penilaian ini dilakukan dengan cara membagikan koestioner kepada para peserta pelatihan tersebut sebanyak 25 responden (peserta) yang meliputi pengetahuan/materi tentang :

1. Proses perencanaan teknik ekploitasi dan pemeliharaan rawa (PTEP).

2. Pelaksanaan konstruksi pemeliharaan rehabilitasi dan peningkatan(PKP).

3. Proses ekploitasi dan pemeliharaan (PEP).

4. Aspek produksi dan pendapatan petani (APP).

5. Pemanfaatan lahan (PML).

Berdasarkan penilaian tersebut tabel terlampir, maka diperoleh angka-angka pada tabel sebagai berikut :

\section{Tabel 4}

Penilaian Pra Test dan Post Test Pada Pelatihan Ekploitasi dan Pemeliharaan Rawa

\begin{tabular}{llcccc}
\hline No. & \multicolumn{1}{c}{ N a m a } & Pra Test & Post Test & $\begin{array}{c}\text { Skor Penambahan } \\
\text { Pengetahuan }\end{array}$ & \% Perubahan \\
\hline 1. & Alwani & 5 & 33 & 28 & 560 \\
\hline 2. & Azhar N. & 11 & 32 & 21 & 190,9 \\
\hline 3. & B. Sitinjak & 9 & 31 & 22 & 244,44 \\
\hline 4. & Bisher Sihit & 15 & 32 & 17 & 113,33 \\
\hline
\end{tabular}


Saridawati

\begin{tabular}{|c|c|c|c|c|}
\hline 5. Cikwi Hasan & 15 & 31 & 16 & 106,66 \\
\hline 6. Effendi M. & 13 & 28 & 15 & 115,38 \\
\hline 7. Gusti D.K & 17 & 31 & 14 & 82,35 \\
\hline 8. Harun Nurasyid & 8 & 35 & 27 & 337,5 \\
\hline 9. Irwan & 10 & 34 & 24 & 240 \\
\hline 10. Ismail & 11 & 30 & 19 & 172,72 \\
\hline 11. Kusdiyono & 16 & 34 & 18 & 112,5 \\
\hline 12. L. Situmorang & 10 & 35 & 25 & 181,81 \\
\hline 13. M. Rizal S. & 11 & 31 & 20 & 250 \\
\hline 14. Manuala Lubis & 10 & 30 & 20 & 200 \\
\hline 15. Masito S. & 12 & 38 & 26 & 216,66 \\
\hline 16. Nurdin H.M. & 11 & 32 & 21 & 190,90 \\
\hline 17. Poniran & 10 & 31 & 21 & 210/nhjghg \\
\hline 18. Robinson M. & 15 & 36 & 15 & 10 \\
\hline 19 Syamsul Bahri & 10 & 25 & 15 & 150 \\
\hline 20. Tom Ngaskarul & 14 & 31 & 17 & 121,42 \\
\hline 21. Ujang Nukman & 9 & 31 & 22 & 244,44 \\
\hline 22. Wabar & 27 & 33 & 6 & 22,22 \\
\hline 23. Warmata Anwar & 7 & 33 & 26 & 371,42 \\
\hline 24. Yuskar & 11 & 31 & 20 & 181,81 \\
\hline 25. Zulkifli B. & 11 & 31 & 20 & 181,81 \\
\hline
\end{tabular}

Tabel 5

Tabel Untuk Menghitung Peranan Pelatihan Terhadap Produktivitas Kerja

\begin{tabular}{|c|c|c|c|c|c|c|}
\hline $\mathrm{Nam} \mathrm{a}$ & $\begin{array}{c}\text { Skor } \\
\text { Penambahan } \\
\text { Pengetahuan }\end{array}$ & $\begin{array}{l}\text { Rankin } \\
\mathrm{g}\end{array}$ & $\begin{array}{c}\text { Produktivita } \\
\text { s } \\
(\%)\end{array}$ & Ranking & di & $\mathrm{di}^{2}$ \\
\hline 1. Alwani & 28 & 25 & 560 & 25 & 0 & 0 \\
\hline 2. Azhar N. & 21 & 15 & 190 & 14.5 & 0.5 & 0.25 \\
\hline 3. B. Sitinjak & 22 & 18.5 & 244.44 & 20.5 & 2 & 4 \\
\hline 4. Bisher Sihit & 17 & 7.5 & 113.33 & 6 & 1.5 & 4.25 \\
\hline 5. Cikwi Hasan & 16 & 6 & 106.66 & 4 & 2 & 4 \\
\hline 6. Effendi M. & 15 & 4 & 115.38 & 7 & 3 & 9 \\
\hline 7. Gusti D.K & 14 & 2 & 82.35 & 2 & 0 & 0 \\
\hline
\end{tabular}




\begin{tabular}{lcccccc}
\hline 8. Harun Nurasyid & 27 & 24 & 337.5 & 23 & 1 & 1 \\
\hline 9. Irwan & 24 & 20 & 240 & 19 & 1 & 1 \\
\hline 10. Ismail & 19 & 10 & 172.72 & 10 & 0 & 0 \\
\hline 11. Kusdiyono & 18 & 9 & 112.5 & 5 & 4 & 24 \\
\hline 12. L. Situmorang & 25 & 21 & 250 & 22 & 1 & 1 \\
\hline 13. M. Rizal S. & 20 & 12.5 & 181.81 & 12 & 0.5 & 0.25 \\
\hline 14. Manuala Lubis & 20 & 22.5 & 200 & 16 & -3.5 & 12.25 \\
\hline 15. Masito S. & 26 & 22.5 & 216.66 & 18 & 4.5 & 20.25 \\
\hline 16. Nurdin H.M. & 21 & 16 & 190.90 & 14.5 & 1.5 & 3 \\
\hline 17. Poniran & 21 & 16 & 210 & 17 & -1 & 1 \\
\hline 18. Robinson M. & 15 & 4 & 100 & 3 & 1 & 1 \\
\hline 19 Samsul Bahri & 15 & 4 & 150 & 9 & -5 & 25 \\
\hline 20. Tom Ngaskarul & 17 & 7.5 & 121.42 & 8 & 0.5 & 0.25 \\
\hline 21. Ujang Nukman & 22 & 18.5 & 244.44 & 20.5 & -2 & 4 \\
\hline 22. Wabar & 6 & 1 & 22.22 & 1 & 0 & 0 \\
\hline 23. Warmata Anwar & 26 & 12.5 & 371.42 & 24 & -1.5 & 2.25 \\
\hline 24. Yuskar & 20 & 12.5 & 181.81 & 12 & 0.5 & 0.25 \\
\hline 25. Zulkifli B. & 20 & 12.5 & 181.81 & 12 & 0.5 & 0.25 \\
\hline
\end{tabular}

Jika tabel di atas dipakai untuk menghitung peranan pelatihan terhadap produktivitas kerja, maka sebagai berikut :

$$
r_{s}=1-\frac{6 \Sigma d i^{2}}{N\left(N^{2}-1\right)}=1-\frac{6(111,5)}{25\left(25^{2}-1\right)}=1-\frac{669}{25(624)}=0,957 \text { atau } 0,96
$$

Dari angka tersebut menunjukkan bahwa pelatihan sangat mempengaruhi produktivitas kerja atau dengan kata lain hubungan dengan produktivitas kerja sangat kuat, penulis berasumsi demikian berdasarkan kriteria besarnya korelasi. Untuk lebih jelas lihat tabel di bawah ini :

\section{Tabel 6}

\begin{tabular}{c|l}
\multicolumn{2}{c}{ Koefisien Korelasi dan Tafsirannya } \\
\hline KOEFISIEN & \multicolumn{1}{|c}{ TAFSIRANNYA } \\
\hline $0,00-0,19$ & Hubungan bisa diabaikan \\
$0,20-0,39$ & Hubungan yang rendah \\
$0,40-0,69$ & Hubungan yang besar \\
$0,70-1,00$ & Hubungan yang kuat \\
\hline
\end{tabular}


Sedangkan untuk menghitung bersarnya pengaruh pelatihan terhadap produktivitas kerja digunakan rumus koefisien

Determinasi $=\mathrm{CD}=\mathrm{r}_{\mathrm{s}}^{2}(100 \%)$

$$
\mathrm{CD}=(0,96)^{2} \cdot 100 \%=92,16 \%
$$

Artinya : bahwa produktivitas kerja dipengaruhi pelatihan sebesar 92,16\%, sisanya dipengaruhi atas faktor lain yang tidak dibahas dalam penelitan ini. Dalam menguji berarti atau tidak hasil dari korelasi yang didapatkan, maka dilakukan uji hipotesis (uji t) dengan rancangan uji hipotesis sebagai berikut :

$\mathrm{HO} ; \mathrm{r}_{\mathrm{s}}=0=$ tidak terdapat peranan yang berarti antara pelatihan dengan produktivitas kerja.

$\mathrm{HO} \mathrm{r}_{\mathrm{s}}=0=$ terdapat peran yang berarti antara pelatihan dengan produktivitas kerja.

$t=r_{s} \sqrt{\frac{N-2}{1-r_{s}^{2}}}=(0,96) \sqrt{\frac{25-2}{1-(096)^{2}}}$

$\mathrm{t}$ tabel $\mathrm{t}(0,05, \mathrm{n}-2)=2,06)$

Dari perhitungan terlihat bahwa nilai t hitung lebih besar dari t tabel, maka Ho ditolak, artinya terdapat hubungan yang signifikan antara pelatihan dengan produktivitas kerja.

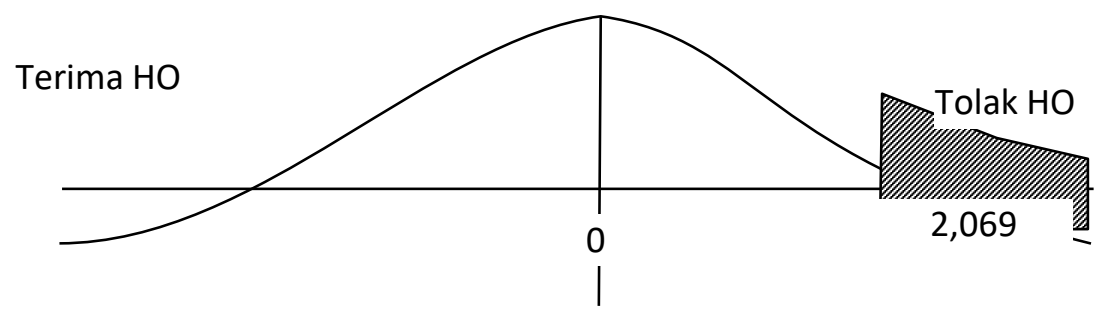

\section{Kesimpulan}

Pada dasarnya selama pelaksanaan Program pelatihan Pusat Pendidikan dan Pelatihan Pegawai Departemen Pekerjaan Umum telah dilaksanakan sesuai kebutuhan, baik pelatihan yang dipersyaratkan dalam pengangkatan pegawai, maupun pelatihan dalam jabatan yang terdiri dari pelatihan struktural, fungsional dan pelatihan teknis. Pelatihan menggunakan berbagai metode sesuai dengan jenis dan kebutuhan pelatihan, adapun instruktur berasal dari dalam lingkungan Departemen Pekerjaan Umum dan dari luar yang ada kaitannya dengan bidang ke-PU-an, dan diaggap mampu serta memenuhi persyaratan-persyaratan tertentu.

Program pelatihan di Pusat Pendidikan dan Pelatihan Departemen Pekerjaan Umum mempunyai hubungan yang kuat dan berperan terhadap produktivitas kerja. Artinya peningkatan produktivitas tenaga kerja berhubungan erat dengan usaha-usaha program pelatihan yang dilaksanakan.

Jenis pelatihan ekploitasi pemeliharaan rawa yang dilakukan oleh PUSDIKLAT Departemen PU bertujuan untuk menambah pengetahuan ketrampilan, kemampuan dari 
pada para pegawai yang menangani bidang tersebut. Oleh karena itu unit pelaksana melakukan evaluasi terhadap para pegawai yang mencakup 5 (lima) faktor penilaian antara lain : penilaian keseluruhan pelatihan dan kunjungan lapangan, penilaian pokok bahasan tertentu, penilaian instruktur tertentu dan penilaian pengelolaan keseluruhan pelatihan serta penilaian pengetahuan peserta (pre test dan post test). 
Saridawati

\section{BIBLIOGRAFI}

Edwin B. Flippo, Moh Masud. (1992). Manajemen Personalia. Jakarta: Erlangga.

Moh Agus Tulus. (1993). Manajemen Sumber Daya Manusia. Jakarta: PT. Gramedia.

Ravianto, J. (1985). Produktivitas dan manusia Indonesia (Vol. 3). Lembaga Sarana Informasi Usaha dan Produktivitas.

Saridawati, Saridawati. (2018). Pengelolaan Dan Pengembangan Sumber Daya Manusia Pada Pt. Atmoni Shamasta Prezki. Syntax Literate; Jurnal Ilmiah Indonesia, 3(9), 107-122.

Terry, George R. (1986). Asas-Asas Manajemen. terj. Winardi. Bandung: Alumni. 